\title{
Production of Nitric Oxide and Nitrosylleghemoglobin Complexes in Soybean Nodules in Response to Flooding
}

\author{
Cristina Sánchez, ${ }^{1}$ Andrew J. Gates, ${ }^{2}$ Georgina E. Meakin, ${ }^{2}$ Toshiki Uchiumi, ${ }^{3}$ Lourdes Girard, ${ }^{4}$ \\ David J. Richardson, ${ }^{2}$ Eulogio J. Bedmar, ${ }^{1}$ and María J. Delgado ${ }^{1}$ \\ ${ }^{1}$ Estación Experimental del Zaidín, CSIC, P. O. Box 419, 18080-Granada, Spain; ${ }^{2}$ School of Biological Sciences, \\ University of East Anglia, Norwich, NR4 7TJ, UK.; ${ }^{3}$ Graduate School of Science and Engineering, Kagoshima University, \\ Kagoshima 890-0065, Japan; ${ }^{4}$ Programa de Genómica Funcional de Procariotes, Centro de Ciencias Genómicas, \\ Universidad Nacional Autónoma de México, Ap. Postal 565-A, Cuernavaca, Morelos, 62271, México
}

Submitted 12 November 2009. Accepted 6 December 2009.

Nitric oxide (NO) has gained interest as a major signaling molecule during plant development and in response to environmental cues. Formation of NO during symbiotic interactions has been reported, but the role and sources of NO in nodules remain unclear. In this work, the involvement of denitrification, performed by the symbiont Bradyrhizobium japonicum, in NO formation in soybean nodules in response to flooding conditions has been investigated by inoculating plants with napA-, nirK-, or nor $C$-deficient mutants. Levels of nitrosylleghemoglobin (LbNO) in flooded nirK and nor $C$ nodules were significantly higher than those observed in wild-type nodules. In addition, nirK and norC nodules accumulated more nitrite and NO, respectively, than wild-type nodules. By contrast, levels of LbNO, nitrite, and NO in flooded napA nodules were lower than in wild-type nodules. These results suggest that $\mathrm{LbNO}$ formation in soybean nodules in response to flooding conditions is caused by nitrite and NO generated from periplasmic nitrate reductase (Nap) and also containing nitrite reductase (NirK) denitrification enzymes. Flooding caused a decrease of nifH expression and nitrogenase activity in wild-type and nor $C$ nodules but not in napA or nirK nodules. Incubation of wild-type and norC nodules with a NO scavenger counteracted the effect of flooding. Under freeliving conditions, $\beta$-galactosidase activity from a nifD''lacZ fusion decreased in a norC mutant, which also accumulated NO in the medium. These results suggest that NO formed by $\mathrm{Cu}$-containing nitrite reductase in soybean nodules in response to flooding has a negative effect on expression of nitrogenase. We propose that $\mathrm{Lb}$ has a major role in detoxifying NO and nitrite produced by bacteroidal denitrification in response to flooding conditions.

Members from the order Rhizobiales are gram-negative bacteria with the unique ability to establish a dinitrogen $\left(\mathrm{N}_{2}\right)$-fixing symbiosis on legume roots and on the stems of some aquatic legumes. Symbiotic nitrogen fixation by the legume-rhizobia couple is a process of both ecological and agricultural impor-

Corresponding author: María J. Delgado; Telephone: +(34) 958181600 (327); Fax: +(34) 958129600; E-mail: mdelgado@eez.csic.es

* The $\boldsymbol{e}$-Xtra logo stands for "electronic extra" and indicates that a supplementary table and a supplementary figure are available online. tance. In the nodule, maintenance of nitrogenase activity is subject to a delicate equilibrium. First, a high rate of oxygen $\left(\mathrm{O}_{2}\right)$-respiration is necessary to supply the energy demands of the $\mathrm{N}_{2}$ reduction process, but $\mathrm{O}_{2}$ also irreversibly inactivates the nitrogenase complex. These conflicting demands are reconciled by control of $\mathrm{O}_{2}$ flux through a diffusion barrier in the nodule cortex, which greatly limits permeability to $\mathrm{O}_{2}$ (Minchin 1997). Oxygen is then delivered to the bacteroids by the plant $\mathrm{O}_{2}$ carrier leghemoglobin (Lb), which is present exclusively in the nodule (Appleby 1992). As such, a very low concentration of free oxygen ( 3 to $30 \mathrm{nM}$ ) is maintained within infected nodule tissue. In response to this dramatic physiological switch, rhizobia initiate the expression of nif and fix genes involved in nitrogen fixation (Fischer 1994).

Nitric oxide (NO) is a ubiquitous gaseous signaling molecule that plays important roles in a wide variety of plant processes, including growth, development, disease, and the abiotic stress resistance responses (Besson-Bard et al. 2008; Delledonne 2005). Several studies have clearly shown the production of $\mathrm{NO}$ in early stages of symbiosis and in mature nodules. It has been reported that a rapid and transient NO production occurs in Lotus japonicus roots inoculated with Mesorhizobium loti (Shimoda et al. 2005) and that modulation of NO levels are involved in the establishment of the symbiosis (Nagata et al. 2008). Functioning nodules also produce NO, and this production has been associated with the bacteroid-containing cells of the fixing zone in alfalfa nodules (Baudouin et al. 2006). Furthermore, NO has shown clear involvement in the auxin-signaling pathway controlling indeterminate nodule formation (Pii et al. 2007). A recent transcriptomal study of NO-responsive genes in Medicago truncatula revealed that NO may regulate important processes of nodule development and functioning (Ferrarini et al. 2008). NO has been reported as a potent inhibitor of nitrogenase activity in soybean (Trinchant and Rigaud 1982), Alnus firma (Sasakura et al. 2006), and Lotus japonicus nodules (Kato et al. 2009; Shimoda et al. 2009). As such, NO could also interfere with $\mathrm{N}_{2}$ fixation by binding to $\mathrm{Lb}$, which would therefore impair Lb functionality by competing with $\mathrm{O}_{2}$ for binding sites. In this context, it has been demonstrated that $\mathrm{NO}$ can bind $\mathrm{Lb}$ to form nitrosylleghemoglobin (LbNO) complexes in soybean nodules (Mathieu et al. 1998; Meakin et al. 2007). In plants, NO is produced under various stress conditions such as hypoxia and low temperature (Dordas et al. 2009; Shimoda et al. 2005). Thus, is timely to address the role of NO in nodules under stress conditions. 
The sources of NO in nodules are unclear. NO may originate from the plant root tissue or from the bacteroids. In plant cells, NO can be produced from nitrite via both nonenzymatic (Bethke et al. 2004) and enzymatic pathways, i.e., those catalyzed by nitrate reductase, that can reduce nitrite to NO as well as nitrate to nitrite (Meyer et al. 2005; Yamasaki et al. 1999; Yamasaki and Sakihama 2000) or by the plasma membranebound nitrite NO-reductase (Stöhr et al. 2001). Also, NO may be produced in plant root tissue from arginine, via an unidentified nitric oxide synthase (NOS)-like enzyme or via an-as-yet uncharacterized process that uses polyamines as substrates (Besson-Bard et al. 2008). In this context, a NOS-like activity has been identified in nodules of Lupinus albus (Cueto et al. 1996), and it has been suggested that a NOS-like enzyme may participate in NO production in $M$. truncatula nodules (Baudouin et al. 2006).

Bacterial denitrification is another likely source of NO in nodules, since nitrite and NO are produced as intermediates during the reduction of nitrate to $\mathrm{N}_{2}$. The soybean symbiont Bradyrhizobium japonicum is an $\alpha$-proteobacterium able to denitrify under both free-living and symbiotic conditions (Bedmar et al. 2005). In B. japonicum, denitrification is dependent on the napEDABC (Delgado et al. 2003), nirK (Velasco et al. 2001), norCBQD (Mesa et al. 2002) and nosRZDYFLX (Velasco et al. 2004) genes that encode the nitrate-, nitrite-, nitric oxide-, and nitrous oxide-reductase systems, respectively. Expression of the B. japonicum denitrification genes has been reported in soybean root nodules, by in situ histochemical detection of $\beta$-galactosidase activity from transcriptional fusions of the nirK, norC, or nosZ promoters with the reporter gene lacZ (Mesa et al. 2004).

Recently, it has been demonstrated that the reduction of nitrate by $B$. japonicum bacteroids contributes to LbNO production within soybean nodules in response to hypoxia (Meakin et al. 2007). However, the sources and role of NO in nodules remain unclear. In this work, we have demonstrated that NO produced in nodules by $B$. japonicum also containing nitrite reductase (NirK) in response to flooding conditions affects nitrogenase genes expression. We have also found that nitrite and NO formed by $B$. japonicum periplasmic nitrate reductase (Nap) and NirK, respectively, are the main sources of $\mathrm{LbNO}$ in nodules in response to flooding.

\section{RESULTS}

\section{NO formation in soybean nodules induced}

\section{by $n a p A$, nirK, or norC B. japonicum mutants.}

In this work, electron paramagnetic resonance (EPR) spectroscopy was used to detect $\mathrm{NO}$ bound to $\mathrm{Lb}$ in intact nodules to form LbNO complexes, UV-visible absorbance spectroscopy was used to quantify the proportion of LbNO complexes in nodule extracts, and free NO was analyzed by using the specific fluorescent probe DAF-FM (4-amino-5-methylamino-2', 7'-difluorofluorescein). A first experiment was performed to investigate the effect of nitrate and flooding in LbNO and free NO formation in soybean nodules by inoculating plants with the wild-type (WT) B. japonicum strain USDA110. Nodules from plants grown in the absence of nitrate formed approximately 7 and $10 \%$ LbNO under normoxic and flooding conditions, respectively (Supplementary Fig. S1A). Under normoxic conditions, the proportion of LbNO increased slightly with the application of nitrate to approximately $18 \%$. However, observation of the absorption spectra from WT nodule extracts of plants treated with nitrate and flooding indicated a significant increase of the proportion of LbNO to approximately $40 \%$. Similarly, basal levels of fluorometrically detected NO were observed in nod- ules of plants grown in the absence of nitrate and subjected or not to flooding. The intensity of fluorescence increased about 1.5- and 3.5-fold in nodules treated with nitrate and grown under normal or flooding conditions, respectively, compared with normoxic plants grown without nitrate. These observations demonstrate that nitrate and flooding conditions induce NO and LbNO formation in soybean nodules. EPR spectra of intact root nodules isolated from nitrate-treated plants inoculated with WT strain were devoid of any LbNO signal but showed a single derivative line shape present at $g \sim$ 2.01 , which can be attributed to saturated radical within the nodule tissue (Fig. 1). Similarly, WT nodules of plants grown in the absence of nitrate did not show any EPR LbNO signal (data not shown). By contrast, WT nodules obtained from nitrate-treated plants subjected to flooding conditions gave a clear LbNO signal with $g$ values at $2.04(\sim 2.01)$ and 1.99 (Fig. 1).

To investigate the contribution of B. japonicum Nap, NirK, and Nor enzymes in $\mathrm{LbNO}$ and $\mathrm{NO}$ formation, plants were inoculated with $B$. japonicum USDA110, napA GRPA1, nirK GRK308, or norC GRC131 strains and were treated with nitrate and subjected or not (referenced herein as control plants) to flooding conditions. As shown in Figure 1, the EPR

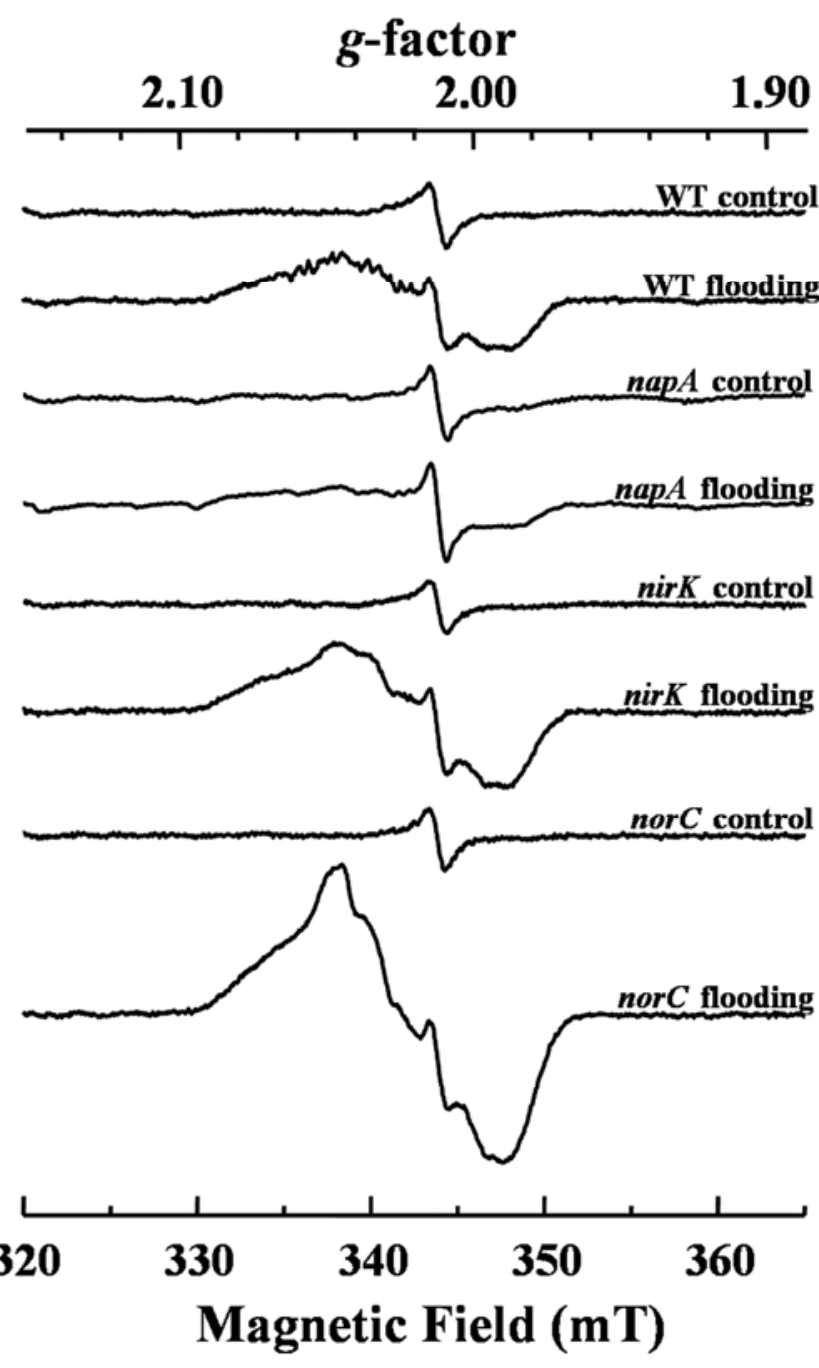

Fig. 1. Electron paramagnetic resonance (EPR) spectra of intact nodules from plants inoculated with wild-type (WT) Bradyrhizobium japonicum USDA110, napA GRPA1, nirK GRK308, or norC GRC131 strains. Plants were subjected or not (control) to flooding conditions. For each strain, a representative EPR spectrum observed from triplicate nodule samples from three different nodule harvests is presented. 
spectrum from flooded norC nodules showed that the LbNO signal was significantly greater than the signal observed from flooded WT nodules. Similarly, the proportion of LbNO from UV-visible spectra of norC nodule extract was twofold higher than that of WT nodules, when subjected to the same conditions (Fig. 2A). Fluorometric NO detection showed that norC nodules accumulated approximately five times more NO than did WT nodules, when subjected to flooding (Fig. 2B). To clarify that the induction of fluorescence observed in WT and nor $C$ nodules was due to $\mathrm{NO}$, flooded nodules were treated
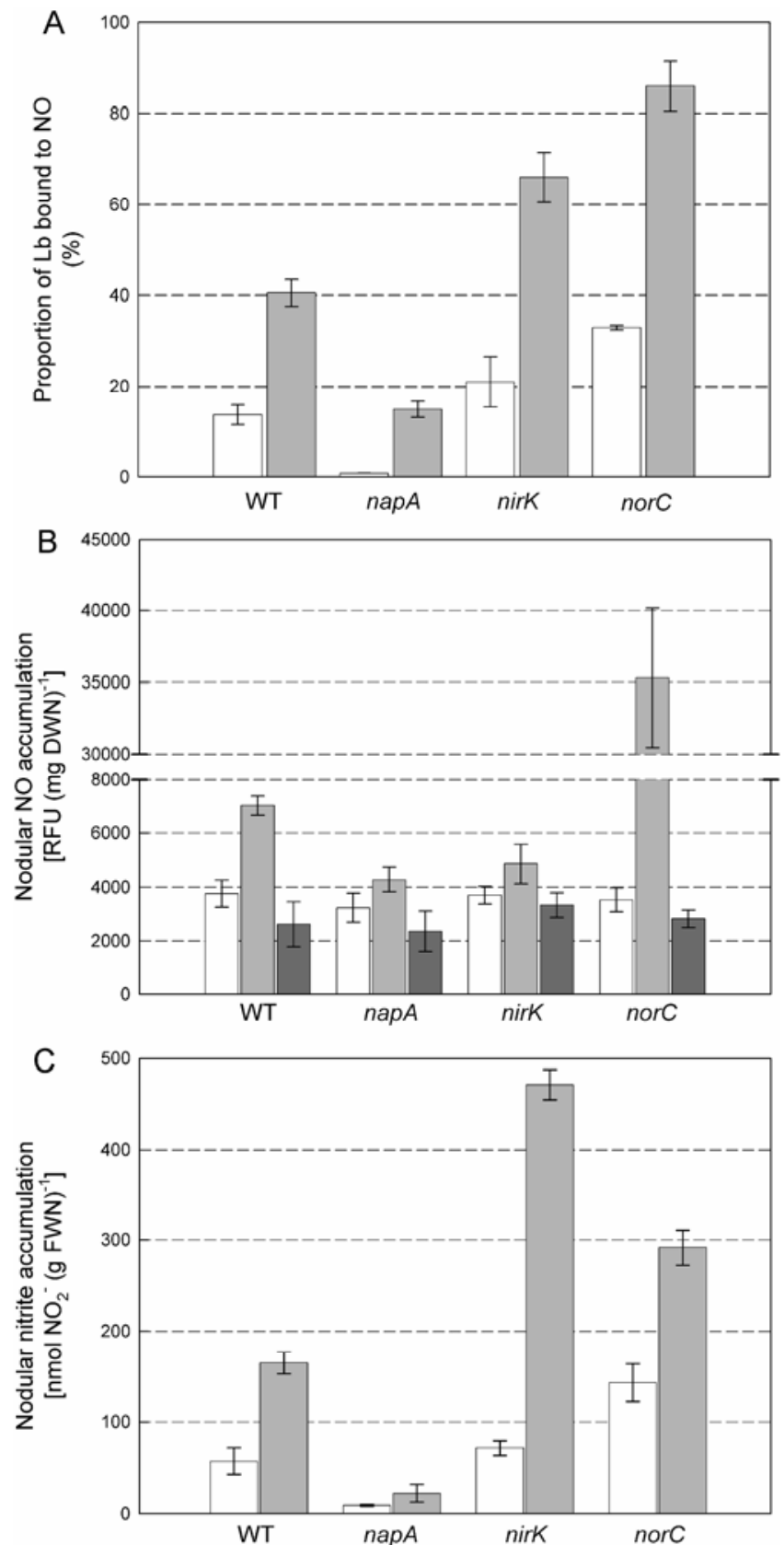

Fig. 2. A, Nitrosylleghemoglobin (LbNO) proportion determined from the UV-visible spectra, B, Nitric oxide (NO) detection using 4-amino-5-methylamino-2', $7^{\prime}$-difluorofluorescein and expressed as relative fluorescence units, and $\mathbf{C}$, nitrite accumulation in nodules. Plants were inoculated with wild-type (WT) Bradyrhizobium japonicum USDA110, napA GRPA1, nirK GRK308, or norC GRC131 strains. Nodules were isolated from control plants (white bars) or plants subjected to flooding conditions (gray bars). In B, flooded nodules were incubated with $2 \mathrm{mM}$ 2-[4-carboxyphenyl]-4,4,5,5-tetramethylimidazoline-1-oxyl-3-oxide (black bars). Data are means \pm standard error from three independent experiments assayed by using six replicates. DWN = dry weight nodule, $\mathrm{FWN}=$ fresh weight nodule. with a NO scavenger (2 mM 2-[4-carboxyphenyl]-4,4,5,5tetramethylimidazoline-1-oxyl-3-oxide [c-PTIO]). In the presence of c-PTIO, fluorescence was clearly suppressed (Fig. 2B), indicating that the response was representative of NO production.

The magnitude of the EPR LbNO signal from nirK nodules subjected to flooding was greater than that observed in WT flooded nodules (Fig. 1). Similarly, the UV-visible spectra demonstrated that levels of $\mathrm{LbNO}$ were about 1.5 times greater in flooded nirK nodules than in WT nodules (Fig. 2A). In addition, approximately three times more nitrite accumulated in nodules from plants inoculated with the nirK mutant and subjected to flooding as compared with those from plants inoculated with the WT strain (Fig. 2C). However, flooding did not induce NO production in nirK nodules as compared with WT nodules (Fig. 2B).

A significant observation was that unlike WT, nirK, or norC nodules, napA nodules consistently failed to give a clear LbNO EPR signal when subjected to flooding (Fig. 1). Also, flooded napA nodules contained very low levels of nitrite compared with WT flooded nodules and control levels of $\mathrm{NO}$ and LbNO (Fig. 2A, B, and C).

Flooding conditions induced about twofold bacteroidal nitrate reductase activity in WT, nirK, and nor C nodules (Table 1). As previously observed by Meakin and associates (2007), nitrate reductase activity was not detected in bacteroids produced by the napA mutant strain and isolated from control nodules (Table 1). Bacteroids from napA flooded nodules exhibited some nitrate reductase activity, although at a rate 10fold lower than in WT bacteroids (Table 1). Wild-type levels of nitrite reductase activity were observed in nirK bacteroids from control plants (Table 1), indicating that NirK is not the only enzyme involved in nitrite reduction in bacteroids. Flooding conditions induced about 1.7-fold nitrite reductase activity in WT bacteroids (Table 1) but not in nirK bacteroids, suggesting the involvement of NirK in the activity induction observed in WT bacteroids in response to flooding conditions (Table 1). NO reductase activity was approximately 1.7-fold higher in WT bacteroids from flooded nodules compared with that from control nodules (Table 1). Wild-type levels of NO reductase activity were observed in norC bacteroids from nodules of either control or flooded plants (Table 1). In support of these findings, similar rates of NO consumption by both WT and norC bacteroids were observed by Meakin and associates (2006), suggesting that Nor is not solely responsible for NO reduction in bacteroids from soybean nodules.

Table 1. Methyl viologen-dependent nitrate reductase (NR), nitrite reductase (Nir), and nitric oxide reductase (Nor) activities in bacteroids ${ }^{\mathrm{z}}$

\begin{tabular}{|c|c|c|c|}
\hline Strain & Genotype & Control & Flooding \\
\hline \multicolumn{4}{|c|}{$\mathrm{NR}$ activity [nmol $\mathrm{NO}_{2}^{-}$produced $\mathrm{min}^{-1}$ (per mg of protein)] } \\
\hline USDA110 & WT & $37 \pm 1$ & $81 \pm 8$ \\
\hline GRPA1 & napA & ND & $8 \pm 1$ \\
\hline GRK308 & nirK & $25 \pm 2$ & $64 \pm 2$ \\
\hline GRC131 & norC & $27 \pm 2$ & $71 \pm 4$ \\
\hline \multicolumn{4}{|c|}{ Nir activity $\left[\mathrm{nmol} \mathrm{NO}{ }_{2}^{-}\right.$consumed $\mathrm{min}^{-1}$ (per mg of protein)] } \\
\hline USDA110 & WT & $1.2 \pm 0.1$ & $2.0 \pm 0.2$ \\
\hline GRK308 & nirK & $1.2 \pm 0.1$ & $1.2 \pm 0.1$ \\
\hline \multicolumn{4}{|c|}{ Nor activity [nmol NO consumed $\min ^{-1}$ (per mg of protein)] } \\
\hline USDA110 & WT & $22 \pm 3$ & $37 \pm 2$ \\
\hline GRC131 & norC & $27 \pm 4$ & $38 \pm 5$ \\
\hline
\end{tabular}

${ }^{\mathrm{z}}$ Plants were inoculated with wild-type (WT) Bradyrhizobium japonicum USDA110, napA GRPA1, nirK GRK308, or norC GRC131 strains. Nodules were isolated from control plants or plants subjected to flooding conditions. Data are means \pm standard error from three independent experiments assayed by using three replicates. $\mathrm{ND}=$ not detected. 
Nitrogenase expression in soybean nodules induced by napA, nirK, or norC B. japonicum mutants.

To assess the effect of NO production within flooded nodules on the expression of the nifH gene (which encodes the $\mathrm{Fe}$ protein of nitrogenase), nifH transcripts were analyzed, using quantitative reverse transcriptase-polymerase chain reaction (RT-PCR). RNA was isolated from nodules of soybean plants that were inoculated with $B$. japonicum USDA110, napA GRPA1, nirK GRK308, or norC GRC131 strains. As shown in Figure 3, nifH mRNA level decreased about five times in WT nodules from plants subjected to flooding conditions compared with that from control plants. Similar to that observed in WT nodules, nifH expression decreased about sixfold in nor $C$ nodules subjected to flooding as compared with norC control nodules (Fig. 3). In contrast to WT or norC nodules, nifH expression was not affected by flooding in napA or nirK nodules (Fig. 3). These results suggest that there is a correlation between the induction of NO production in response to flooding (Fig. 2B) and the decrease of nifH expression observed in WT and norC nodules (Fig. 3). When WT or norC nodules harvested from flooded plants were treated with the NO scavenger c-PTIO, nifH expression was enhanced about threefold compared with that observed in the absence of c-PTIO (Fig. 3), indicating that nifH expression was partially recovered when NO was removed by c-PTIO.

Under nonflooding conditions, the decrease of nifH expression of about 25,35 , and $40 \%$ observed in napA, nirK, and nor $C$ nodules, respectively, compared with that in WT nodules (Fig. 3) was not due to NO, since similar levels of NO were produced by either nonflooded WT, napA, nirK, or norC nodules (Fig. 2B). Previous work from our group demonstrated that disruption of the denitrification pathway by mutation in denitrification genes reduces expression of the $c b b_{3}$-type oxidase (Bueno et al. 2009). Since $c b b_{3}$ oxidase is responsible for oxygen respiration to provide ATP to nitrogenase, a lower expression of this oxidase in bacteroids might affect oxygen consumption rates by the cells, as it has been observed in free-living cells and, consequently, might prevent maximal expression of the nif genes, which require very low oxygen conditions.

The effect of flooding on the transcriptional level of other nitrogenase-related genes was also assessed in nodules of soybean plants inoculated with $B$. japonicum USDA110. Table 2 shows that, similarly to nifH transcripts, levels of nifD transcripts significantly decreased in WT flooded nodules. However, in flooded nodules, similar transcription levels of fixA and nifS genes were observed compared with those detected in nodules isolated from control plants (Table 2).

In addition, we examined the nitrogen-fixing activity of the nodules by analyzing acetylene reduction activity. Since it has been previously demonstrated that the Lb concentration measured fluorimetrically correlated with nitrogenase activity (LaRue and Child 1979), we also analyzed nitrogen-fixing activity of the nodules, by measuring $\mathrm{Lb}$ content in the nodules. As shown in Table 3, nitrogenase activity as well as Lb content

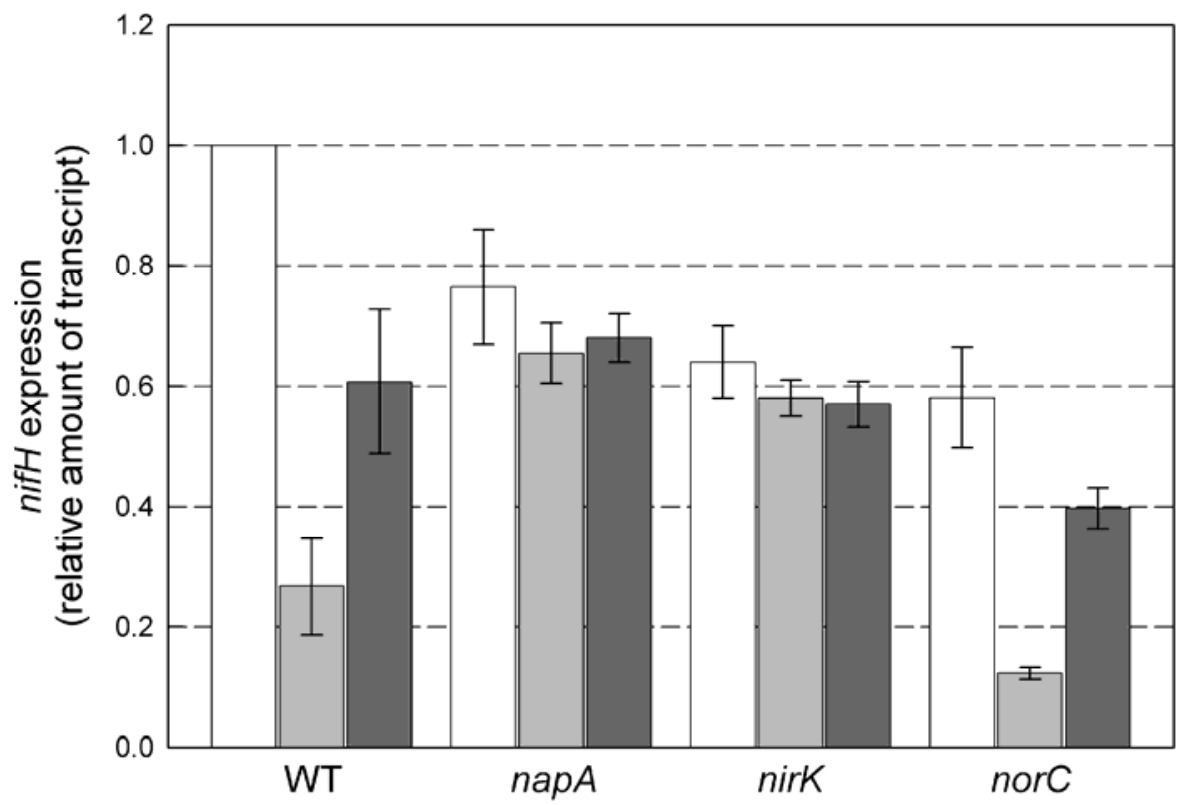

Fig. 3. Expression of nifH in nodules by quantitative reverse transcriptase-polymerase chain reaction. Plants were inoculated with wild-type (WT) Bradyrhizobium japonicum USDA110, napA GRPA1, nirK GRK308, or norC GRC131 strains. Nodules were isolated from control plants (white bars) or plants subjected to flooding conditions (gray bars). Flooded nodules were incubated with $2 \mathrm{mM}$ 2-[4-carboxyphenyl]-4,4,5,5-tetramethylimidazoline-1-oxyl-3oxide (black bars). Data are means \pm standard error from three independent RNA samples assayed by using three replicates.

Table 2. Expression of nifH, nifD, fixA, and nifS in nodules ${ }^{2}$

\begin{tabular}{llll}
\hline & & \multicolumn{2}{c}{ Relative amount of transcript } \\
\cline { 2 - 4 } Gene & \multicolumn{1}{c}{ Description } & Control & Flooding \\
\hline nifH & Dinitrogenase reductase protein & $1.000 \pm 0.000$ & $0.266 \pm 0.080$ \\
nifD & Nitrogenase molybdenum-iron protein alpha chain & $1.000 \pm 0.000$ & $0.299 \pm 0.077$ \\
fixA & Electron transfer flavoprotein beta chain & $1.000 \pm 0.000$ & $0.935 \pm 0.007$ \\
nifS & Nitrogenase metalloclusters biosynthesis protein & $1.000 \pm 0.000$ & $0.903 \pm 0.071$ \\
\hline
\end{tabular}

${ }^{\mathrm{z}}$ Expression was measured by quantitative reverse transcriptase-polymerase chain reaction in nodules from plants inoculated with Bradyrhizobium japonicum USDA110. Data are means \pm standard error from three independent RNA samples assayed by using three replicates. Nodules were isolated from control plants or plants subjected to flooding conditions. 
decreased about two times by flooding in WT and norC nodules but not in napA or nirK nodules.

nifD expression in nirK and norC B. japonicum mutants.

In order to demonstrate the involvement of NO in the expression of genes responsible for the synthesis of nitrogenase, a translational $l a c Z$ fusion with the promoter region of the nifD gene (which encodes the $\alpha$-subunit of the MoFe protein of nitrogenase) was used in regulatory studies performed under free-living conditions. It has been previously reported that

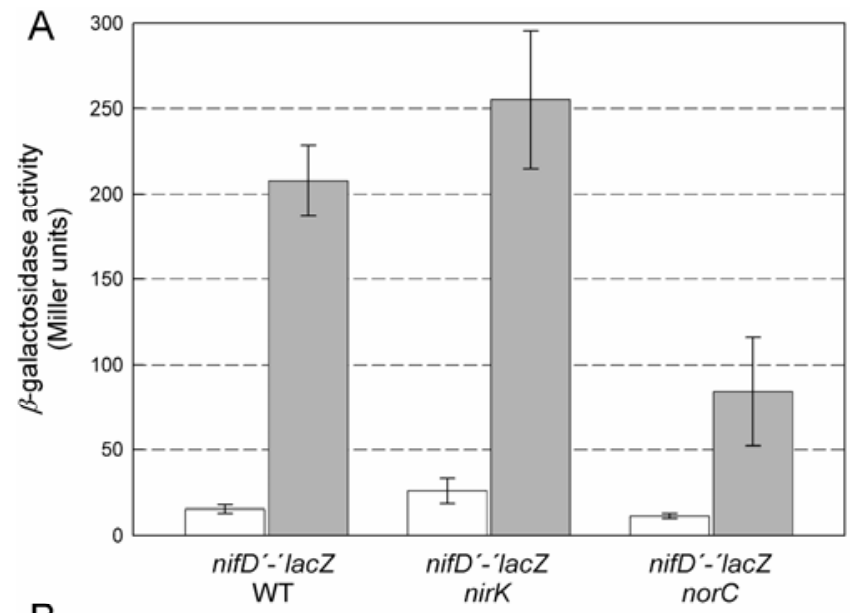

B

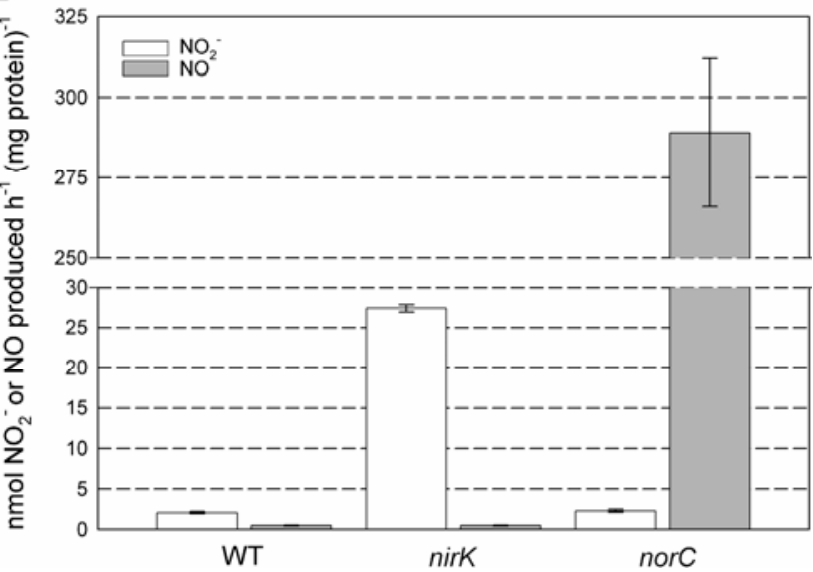

Fig. 4. A, $\beta$-galactosidase activity from a nif $D^{\prime}-\eta a c Z$, translational fusion in wild-type (WT) Bradyrhizobium japonicum 1042, nirK 0110, and norC 0410 strains. Cells were incubated in yeast extract-mannitol (YEM) medium supplemented with $10 \mathrm{mM} \mathrm{KNO}_{3}$ under aerobic (white bars) or anaerobic (gray bars) conditions. Data are means with standard error from at least two different cultures, assayed in triplicate. B, Nitrite $\left(\mathrm{NO}_{2}^{-}\right)$ (white bars) and nitric oxide (NO) (gray bars) produced by WT $B$. japonicum USDA110, nirK GRK308, and norC GRC131 strains. Cells were incubated in YEM medium supplemented with $10 \mathrm{mM} \mathrm{KNO}_{3}$ under anaerobic conditions. Data are means with standard error from at least two different cultures, assayed in triplicate. cells of a $B$. japonicum mutant strain with a null mutation in the nirK or norC genes accumulated nitrite and nitric oxide, respectively, when cultured under nitrate respiring conditions (E. F. Robles, M. J. Delgado, T. Krell, F. Cutruzzolà, and E. J. Bedmar, unpublished; Velasco et al. 2001). The effect of nitrite and $\mathrm{NO}$ on expression of nifD was investigated by analyzing $\beta$-galactosidase activity in cells of WT strain $B$. japonicum 1042 and nirK 0110 and norC 0410 mutants that contain a chromosomally integrated translational nifD'- $7 a c Z$ fusion (Fig. 4A). After aerobic growth, cells of strains 1042, 0110, and 0410 showed basal levels of $\beta$-galactosidase activity (Fig. 4A). When cells were incubated under anaerobic conditions, an increase of about 10 -fold of $\beta$-galactosidase activity was observed in WT and nirK cells compared with the activity detected in cells grown in air (Fig. 4A). Interestingly, the level of $\beta$ galactosidase activity observed in the nor $C$ mutant strain 0410 was about threefold lower than that observed in either WT or nirK cells (Fig. 4A). Under our experimental conditions, norC cells accumulated NO after addition of nitrite to the reaction chamber (described below) (Fig. 4B). In control experiments in the absence of nitrite, norC cells did not accumulate NO (data not shown). After 3 days of incubation under anaerobic conditions with nitrate, nitrite was accumulated in nirK growth medium (Fig. 4B). Under free-living denitrifying conditions, methyl viologen (MV)-dependent nitrate reductase and nitrite reductase activities were about 10 times higher compared with those observed under aerobic conditions (Table 4). Of nitrateand nitrite-reductase activities detected in anaerobic growth cells, 88 and $93 \%$ correspond to Nap and NirK enzymes, respectively. Nitric oxide reductase activity was also induced about fivefold in cells grown under nitrate-respiring conditions as compared with aerobically grown cells, and $75 \%$ of such activity was due to Nor encoded by norCBQD genes (Table 4). The strong induction of NirK and Nor activities under denitrifying conditions might explain the absence of significant levels of nitrite and NO produced by WT cells.

Table 4. Methyl viologen (MV)-dependent nitrate reductase (NR), nitrite reductase (Nir), and nitric oxide reductase (Nor) activities in free-living cells ${ }^{2}$

\begin{tabular}{|c|c|c|c|}
\hline Strain & Genotype & Aerobic & Anaerobic \\
\hline \multicolumn{4}{|c|}{$\mathrm{NR}$ activity $\left[\mathrm{nmol} \mathrm{NO}{ }_{2}^{-}\right.$produced $\left.\mathrm{min}^{-1}(\text { mg protein })^{-1}\right]$} \\
\hline USDA110 & WT & $6 \pm 1$ & $53 \pm 3$ \\
\hline GRPA1 & napA & $5 \pm 1$ & $6 \pm 1$ \\
\hline \multicolumn{4}{|c|}{ Nir activity $\left[\mathrm{nmol} \mathrm{NO}{ }_{2}^{-}\right.$consumed $\left.\min ^{-1}(\text { mg protein })^{-1}\right]$} \\
\hline USDA110 & WT & $2.1 \pm 0.4$ & $28 \pm 4$ \\
\hline GRK308 & nirK & $2.5 \pm 0.2$ & $2 \pm 0.2$ \\
\hline \multicolumn{4}{|c|}{ Nor activity [nmol NO consumed $\min ^{-1}(\mathrm{mg} \text { protein })^{-1}$ ] } \\
\hline USDA110 & WT & $47 \pm 4$ & $257 \pm 23$ \\
\hline GRC131 & norC & $43 \pm 6$ & $63 \pm 2$ \\
\hline
\end{tabular}

${ }^{\mathrm{z}}$ B. japonicum USDA110, napA GRPA1, nirK GRK308 and norC GRC131 strains were incubated in yeast extract-mannitol medium supplemented with $10 \mathrm{mM} \mathrm{KNO}_{3}$ under aerobic or anaerobic conditions. Data are means \pm standard error from three independent experiments assayed by using three replicates.

Table 3. Acetylene reduction activity (ARA) and leghemoglobin $(\mathrm{Lb})$ content in nodules ${ }^{\mathrm{z}}$

\begin{tabular}{|c|c|c|c|c|c|}
\hline \multirow[b]{2}{*}{ Strain } & \multirow[b]{2}{*}{ Genotype } & \multicolumn{2}{|c|}{$\operatorname{ARA}\left(\mathrm{nmol} \mathrm{C}_{2} \mathrm{H}_{2} \mathrm{~h}^{-1}\right.$ per gram of $\left.\mathrm{FWN}\right)$} & \multicolumn{2}{|c|}{ Lb content (mg of Lb per gram of FWN) } \\
\hline & & Control & Flooding & Control & Flooding \\
\hline USDA110 & WT & $115 \mathrm{aA}$ & $65 \mathrm{bB}$ & $5.90 \mathrm{bA}$ & $3.24 \mathrm{bB}$ \\
\hline GRPA1 & napA & $133 \mathrm{aA}$ & $112 \mathrm{aA}$ & $6.96 \mathrm{aA}$ & $5.17 \mathrm{aB}$ \\
\hline GRK308 & nirk & $126 \mathrm{aA}$ & $124 \mathrm{aA}$ & $6.48 \mathrm{abA}$ & $5.17 \mathrm{aB}$ \\
\hline GRC131 & norC & $138 \mathrm{aA}$ & 69 bB & $5.57 \mathrm{bA}$ & $3.34 \mathrm{bB}$ \\
\hline
\end{tabular}

${ }^{\mathrm{z}}$ Plants were inoculated with the wild-type USDA110, napA GRPA1, nirK GRK308, or norC GRC131 strains. Nodules were isolated from control plants or plants subjected to flooding conditions. Values in a column followed by the same lower-case letter and values in a row followed by the same capital letter are not significantly different as determined by the Tukey highly significant differences test at $P \leq 0.05$. FWN $=$ fresh weight nodule. 


\section{DISCUSSION}

In this study, we used a combination of EPR and UV-visible spectroscopies to detect NO bound to $\mathrm{Lb}$ in nodules to form LbNO complexes. The EPR signal produced by LbNO complexes has been previously established by incubating purified, dithionite-reduced soybean leghemoglobin $a$ with nitrite (Meakin et al. 2007) or with a NO donor (Mathieu et al. 1998). By using these approaches, we have previously demonstrated that nitrate and hypoxia cause an increase in LbNO formation within soybean nodules (Meakin et al. 2007). In order to establish the physiological conditions that induce NO formation in soybean nodules, we subjected plants to a physiological stress typical for soybean crops, i.e., flooding, which provokes hypoxic stress caused by water-logging on the soil (Bacanamwo and Purcell 1999; Bailey-Serres and Voesenek 2008). Supporting previous results (Meakin et al. 2007), we have demonstrated that maximal formation of LbNO complexes in soybean nodules require nitrate and flooding conditions.

Several mechanisms by which NO could be produced during plant-rhizobia interactions have been proposed (Pauly et al. 2006). The denitrification pathway is one candidate, since nitrite and NO are intermediates of nitrate reduction to $\mathrm{N}_{2}$. In fact, it has been suggested that nitrate reduction by B. japonicum bacteroids contributes to the formation of LbNO complexes in soybean nodules in response to hypoxia (Meakin et al. 2007). In agreement with these findings, we found here that, in soybean nodules in which the denitrification pathway is disrupted, LbNO formation in response to flooding conditions was significantly reduced when plants were inoculated with a napAdeficient mutant. Furthermore, we have also demonstrated that nitrite produced by Nap, which accumulates in nirK nodules, as well as NO produced by NirK, formation of which increases in norC nodules, are mainly responsible for the increase of LbNO complexes in soybean nodules in response to flooding. These results suggest that both nitrite and NO produced within the reducing environment of the nodule as intermediates of the denitrification process are sources of LbNO. In contrast to our observations, it has been recently suggested that NirK is not involved in nitrite accumulation or LbNO formation in soybean nodules from plants subjected to hypoxia (Meakin et al. 2007). The apparent discrepancy with the results presented here could be due to the different plant growth conditions. In the study by Meakin and associates (2007), plants were subjected to hypoxia artificially, by transferring plants into bottles containing nutrient solution with $4 \mathrm{mM} \mathrm{KNO}_{3}$ and sparging with argon for $15 \mathrm{~min}$. In this work, we used a physiological stress, flooding, to create hypoxia by submerging pots in mineral solution with $1 \mathrm{mM} \mathrm{KNO}$. These different experimental conditions did result in different levels of LbNO in WT nodules (70\% [Meakin et al. 2007] versus $40 \%$ in this work), which could explain the different phenotype for the nirK mutant found in these studies. It has been proposed in Medicago truncatula-Sinorhizobium meliloti symbiosis that the denitrification pathway is not involved in NO production in nodules (Baudouin et al. 2006). Therefore, it may be possible that bacterial denitrification plays a role in NO production within nodules when roots are subjected to specific physiological conditions such as flooding stress.

The presence of basal levels of LbNO detected by UV-visible spectroscopy as well as free NO in nodules from plants grown in the absence of nitrate suggests the involvement of other sources of NO, independent of nitrate, such as a NOSlike activity. A NOS-like activity has been reported in lupine nodules by Cueto and associates (1996) and recent studies have suggested that a NOS-like enzyme contributes to NO production in M. truncatula nodules (Baudouin et al. 2006), but whether a plant NOS is present and functional in soybean nodules is unknown. Similarly, the presence of basal levels of LbNO and NO in napA flooded nodules with nitrate suggests the involvement of other sources of NO, independent of the denitrification pathway, possibly arising from the action of plant enzymes such as one or both a nitrate reductase and a NOS-like enzyme.

The involvement of Nap, NirK, and Nor enzymes in LbNO formation in soybean nodules in response to flooding conditions has also been investigated by analyzing MV-dependent nitrate, nitrite, and nitric oxide reductase activities in bacteroids from nodules of plants inoculated with the WT B. japonicum strain USDA110 and napA GRPA1, nirK GRK308, or norC GRC131 mutant strains. Levels of MV-dependent nitrate reductase activity in bacteroids of $B$. japonicum cells lacking the functional napA gene demonstrated that 100 and $90 \%$ of activity detected in WT bacteroids from control and flooded nodules, respectively, was due to the B. japonicum Nap enzyme. However, the presence of WT levels of nitrite reductase activity in nirK bacteroids from control plants suggests that another way exists by which nitrite may be reduced in bacteroids in the absence of NirK. In B. japonicum, the published genome sequence (Kaneko et al. 2002) reveals the presence of a $\operatorname{nir} B$ gene, which may encode an assimilatory nitrite reductase that reduces nitrite to ammonium (Lin and Stewart 1998). However, whether this enzyme is active in nirK bacteroids has yet to be addressed. In bacteroids from flooded nodules, $58 \%$ of nitrite reductase activity corresponded to NirK, suggesting that this enzyme may be responsible for the nitrite accumulation and LbNO formation observed in flooded nirK nodules. No differences of NO reductase activity were observed between norC and WT bacteroids from flooded nodules, probably due to the low levels of activity observed in bacteroids as compared with free-living cells. However, a significant increase in NO formation was observed in norC nodules compared with WT nodules, indicating that Nor is involved in NO reduction in nodules under flooding stress conditions.

Several studies have reported direct or indirect evidence for the production of NO in mature nodules (Baudouin et al. 2006; Pii et al. 2007; Shimoda et al. 2009). From the studies above, the question of the possible role of NO in nodules is raised. A direct inhibition of nitrogenase activity by NO has been demonstrated in vitro (Trinchant and Rigaud 1982). It has also been reported that artificial application of a NO donor (sodiumnitroprussiate [SNP] or $S$-nitroso, $N$-acetyl penicillamine [SNAP]) decreased nitrogen fixation activity in Lotus japonicus (Kato et al. 2009; Shimoda et al. 2009) and Alnus firma root nodules (Sasakura et al. 2006). Very recently, Kato and associates (2009) have demonstrated the involvement of NO in the inhibition of nitrogenase activity after the addition of nitrate to Lotus japonicus plants. However, the effect of NO on nitrogenase gene expression was not fully explored. In this work, it has been demonstrated for the first time that NO produced in nodules through bacteroidal denitrification in response to flooding conditions decreases expression of the nifH gene that encodes the $\mathrm{Fe}$ protein of the nitrogenase complex. Since nitrite was also proposed as an inhibitor of nitrogenase activity (Trinchant and Rigaud 1982), it was interesting to analyze nifH transcription in flooded nirK nodules. Although a significant increase of nitrite and LbNO complexes were detected in nirK flooded nodules as compared with WT nodules, nifH transcription was not affected. This result rules out nitrite as a possible inhibitor of nifH gene expression. In napA or nirK flooded nodules, in which NO production from denitrification is blocked, nifH expression was unaffected. These observations strongly support the hypothesis that NO produced under flooding conditions by NirK is involved in the decrease of nifH expression. 
Because NO is cytotoxic, its accumulation by loss of NO reductase activity is a lethal event in denitrifiers (van Spanning et al. 2005, 2007; Zumft et al. 1997). In order to establish whether or not the NO effect on nifH expression in nodules is a general effect in gene regulation, we analyzed expression in nodules of other genes required for nitrogen fixation, such as nifD, encoding the $\alpha$-subunit of the MoFe protein of nitrogenase, fix $A$, encoding a $\beta$-chain of an electron transfer flavoprotein, and nifS, encoding a protein involved in biosynthesis of the metal-containing centers in nitrogenase. Since fixA and nifS expression were not affected in flooded WT nodules, in which NO production was induced, we rule out the possibility that NO has a general toxic effect in gene regulation in nodules.

Flooding induced levels of LbNO complexes in nirK nodules compared with that in WT nodules. However, this stress did not affect nitrogenase activity in nirK nodules as compared with the WT nodules, in which nitrogenase activity was significantly decreased. Although LbNO formation was significantly enhanced by flooding in norC nodules, when compared with WT nodules, nitrogenase activity rates were very similar in both WT and norC flooded nodules. These observations lead us to suggest that increase of LbNO complexes in nodules does not impair $\mathrm{N}_{2}$ fixation. We propose an additional role for $\mathrm{Lb}$ in root nodules, i.e., scavenging $\mathrm{NO}$ or nitrite formed during denitrification by the action of NirK or Nap and protecting nitrogenase activity. In support of our hypothesis, it has been proposed that the presence of large amounts of Lb in root nodules in which only a minimum proportion is bound to oxygen and which has a high affinity for NO can act as a NO scavenger modulating NO bioactivity (Herold and Puppo 2005). This may also be a function of nonsymbiotic hemoglobins, since it has been very recently shown that overexpression of class 1 nonsymbiotic plant hemoglobins enhances symbiotic $\mathrm{N}_{2^{-}}$ fixation activity by removing $\mathrm{NO}$ as an inhibitor of nitrogenase (Shimoda et al. 2009). Under denitrifying free-living conditions NirK and Nor enzymes are highly active and may function to detoxify nitrite and NO, respectively, since nirK and nor $C$ mutant strains are defective in anaerobic growth, as previously shown by Velasco and associates (2001) and Mesa and associates (2002). However, under symbiotic conditions, bacteroidal nitrite reductase and NO reductase activities are, respectively, about 14 and seven times lower than those detected under free-living anaerobic conditions. These observations allow us to propose that, in nodules, it is Lb and not the NirK or Nor enzymes that acts as the main system for detoxifying nitrite and NO produced by bacteroidal denitrification in response to flooding conditions.

The involvement of NO produced by NirK in expression of nitrogenase genes has also been confirmed under free-living conditions by analyzing $\beta$-galactosidase activity of a nifD'lacZ translational fusion. After incubation under anaerobic conditions, expression of nifD was decreased in a nor $C$ mutant that accumulated NO in the medium. However, nitrite accumulation in nirK growth medium did not affect nifD expression. These observations strongly support the results found under symbiotic conditions in which, in WT and norC flooded nodules, induction of NO formation correlated well with a decrease in nifH expression. In contrast to symbiotic conditions, WT free-living cells grown under anaerobic conditions did not accumulate NO and, consequently, nifD expression was unaffected. The different NO reductase activity rates found in both B. japonicum free-living and symbiotic WT cells might explain the discrepancy found in NO accumulation and nitrogenase expression in both $B$. japonicum forms in response to low oxygen conditions. Our observations in free-living conditions confirmed the results found under symbiotic conditions and allow us to propose that NO produced by NirK is a potential inhibitor of nitrogenase gene expression. However, the mechanism of such inhibition is still unknown. NO is supposed to be a potent inhibitor of the $\mathrm{O}_{2}$ sensor FixL, which is a component of the FixLJ/FixK $\mathrm{K}_{2}$ regulatory cascade, which controls $\mathrm{N}_{2}$ fixation (Fischer 1994; Gilles-González et al. 1994; Winkler et al. 1996). Alternatively, it is also possible that NO reacts directly with the $\mathrm{N}_{2}$ fixation regulatory protein NifA (Fischer 1994), inactivating the protein in a similar way as it has been demonstrated for the $\mathrm{O}_{2}$-responsive regulator FNR in Escherichia coli (Cruz-Ramos et al. 2002; Pullan et al. 2008). Since NifA is the direct trancriptional activator of $\mathrm{N}_{2}$ fixation genes, a possible effect of $\mathrm{NO}$ on the regulation of the $\mathrm{N}_{2}$ fixation genes via this activator would result in a widespread effect on the transcription of all targets of NifA. Surprisingly, our results show that transcription of two of these targets, fixA and nifS, is not affected by the presence of NO in flooded WT nodules. Recently, Mesa and associates (2008) have suggested that the FixK $_{1}$ regulon contains a substantial number of negatively controlled genes, most of which belong to the group of genes activated by the NifA protein. In those studies, nifD and nifH genes belong to that group of genes, but fixA and nifS genes do not (Mesa et al. 2008). The authors propose that a decrease in the oxygen concentration to intermediate levels induces the FixLJ-FixK cascade and, consequently, FixK $_{1}$ but still represses some NifA-dependent genes via FixK ${ }_{1}$. When the oxygen concentration drops further, cells may accumulate higher levels of the active NifA protein, which would gradually override the transient repression by FixK $_{1}$. If NifA protein is inactivated by the presence of $\mathrm{NO}$ in nodules subjected to flooding, the repression will not be overcome. The mechanism involved in the downregulation of nitrogenase genes by NO is the focus of future investigations.

\section{MATERIALS AND METHODS}

\section{Bacterial strains and growth conditions.}

B. japonicum USDA110 (United States Department of Agriculture, Beltsville, MD, U.S.A.) and napA GRPA1 (Delgado et al. 2003), nirK GRK308 (Velasco et al. 2001), and norC GRC131 (Mesa et al. 2002) mutant derivative strains were used in this study. To monitor nifD expression in free-living cells, plasmid pRJ1042 (Acuña et al. 1987), containing a nifD'- $D_{a c Z}$ translational fusion, was integrated by homologous recombination into the chromosome of $B$. japonicum USDA110, GRK308, and GRC131, resulting in strains 1042, 0110, and 0410, respectively. Integration of the fusion plasmid into the chromosome was tested by hybridizations performed with digoxigenin-dUTP-labeled lacZ DNA as a probe. The chemiluminescence method was applied to detect hybridization bands. B. japonicum strains were routinely grown in peptone salts-yeast extract medium (Regensburger and Hennecke $1983)$ at $28^{\circ} \mathrm{C}$. For determination of $\beta$-galactosidase activity and nitrite and NO accumulation in free-living conditions, cells were grown aerobically or anaerobically for $72 \mathrm{~h}$ at $30^{\circ} \mathrm{C}$ in yeast extract-mannitol (YEM) medium (Vincent 1974) sup-

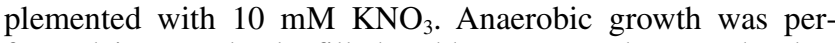
formed in completely filled, rubber-stoppered serum bottles. Initial optical density at $600 \mathrm{~nm}$ of the cultures was about 0.3 . Antibiotics were added to cultures at the following concentrations $\left(\mu \mathrm{g} \mathrm{m}^{-1}\right)$ : chloramphenicol, 15 ; tetracycline, 100; spectinomycin, 200; streptomycin, 200; kanamycin, 200.

\section{Plant growth conditions.}

Soybean (Glycine max L. Merr. cv. Williams) seeds were surface-sterilized with $96 \%$ ethanol ( $\mathrm{vol} / \mathrm{vol})$ for $30 \mathrm{~s}$, were immersed in $\mathrm{H}_{2} \mathrm{O}_{2}(15 \%$, vol/vol $)$ for $8 \mathrm{~min}$, and then, were 
washed with sterile water and germinated in darkness at $28^{\circ} \mathrm{C}$. Selected seedlings were planted in autoclaved pots filled with a sand-vermiculite mixture (1:1). Plants (four per pot) were inoculated at sowing with $1 \mathrm{ml}$ of a single bacterial strain $\left(10^{8}\right.$ cells per milliliter) and were grown in a controlled environmental chamber under conditions previously described (Delgado et al. 1998). Plants were watered four times a week, alternately with water and with a nitrogen-free mineral solution (Rigaud and Puppo 1975). To investigate the effect of plant inoculation with B. japonicum napA, nirK, or norC mutants in LbNO and $\mathrm{NO}$ formation and in order to induce denitrification activity, after growth for 15 days, plants were provided with the same mineral solution supplemented with $4 \mathrm{mM} \mathrm{KNO}_{3}$. It has previously been demonstrated that treatment of plants with $4 \mathrm{mM}$ $\mathrm{KNO}_{3}$ results in denitrification activity and it does not inhibit nodule formation or nitrogenase activity (Meakin et al. 2007; Mesa et al. 2004). After growth for 28 days, plants were subjected to flooding as previously described (Bacanamwo and Purcell 1999) by submerging pots to $1 \mathrm{~cm}$ above substrate level in a quarter-strength mineral solution. The solution level was maintained by daily additions of solution, which was added gently to avoid aeration. Nonflooded treatments (control plants) received the quarter-strength mineral solution four times a week. Nodules were harvested from 34-day-old plants and were frozen into liquid nitrogen and stored at $-80^{\circ} \mathrm{C}$, except those nodules to be used for enzyme activities and NO determination.

\section{Bacteroid isolation.}

Bacteroids were prepared as previously described (Mesa et al. 2004). In brief, $1.5 \mathrm{~g}$ of fresh nodules were ground in 7.5 $\mathrm{ml}$ of $50 \mathrm{mM}$ Tris/ $\mathrm{HCl}$ (pH 7.5) supplemented with $250 \mathrm{mM}$ mannitol. The homogenate was filtered through four layers of cheesecloth and was centrifuged at $250 \times g$ at $4^{\circ} \mathrm{C}$ for 5 min to remove nodule debris. The resulting supernatant was recentrifuged at $12,000 \times g$ at $4^{\circ} \mathrm{C}$ for $10 \mathrm{~min}$ to pellet the bacteroids. The bacteroids were washed twice with $50 \mathrm{mM}$ Tris/ $\mathrm{HCl}(\mathrm{pH}$ 7.5) and were resuspended in a final volume of $2.5 \mathrm{ml}$.

\section{Analytical methods.}

For determination of MV-dependent nitrate and nitrite reductase activities, aliquots of bacteroid or free-living cell preparations ( 0.2 to $0.4 \mathrm{mg}$ of protein) were added to a reaction mixture $\left(\mathrm{KNO}_{3}, 10 \mathrm{mM}\right.$ or $\mathrm{NaNO}_{2}, 200 \mu \mathrm{M}$; MV, $200 \mu \mathrm{M}$; phosphate buffer, $\mathrm{pH} 7.5,10 \mathrm{mM}$ ), and reactions were started with the addition of sodium dithionite. The reactions were run at $30^{\circ} \mathrm{C}$ for $15 \mathrm{~min}$ and were stopped through the oxidation of the sodium dithionite by vortexing. Controls were run in parallel but, in these reactions, the sodium dithionite was oxidized at the start of the reaction. Nitrite was estimated after diazotation by adding the sulfanilamide/naphthylethylene diamine dyhydrochloride reagent (Nicholas and Nason 1957).

For determination of NO reductase activity in bacteroids and free-living cells, a kinetic MV-dependent assay was used. For each assay, a 3-ml cuvette was filled with $2.5 \mathrm{ml}$ of $10 \mathrm{mM}$ phosphate buffer ( $\mathrm{pH} 7.5), 100 \mu$ l of bacteroid preparation or cell solution (0.2-0.4 mg protein), and $25 \mu \mathrm{l}$ of $100 \mathrm{mM} \mathrm{MV}$ solution, was sealed with a mini suba seal, and was made anaerobic by sparging with oxygen-free nitrogen gas for $10 \mathrm{~min}$. A $100-\mathrm{mM}$ sodium dithionite solution was freshly made and sparged before its addition with a gas-tight Hamilton syringe to the cuvette. Enough sodium dithionite was added to turn the solution blue, with an absorbance of approximately 2 at 600 $\mathrm{nm}$ in the spectrophotometer (DW-2000 [SLM-Aminco Instruments Inc., Rochester, N Y, U.S.A.] or U-3310 [Hitachi HighTechnologies, Tokyo]). Once a steady base line was observed, $100 \mu \mathrm{l}$ of a saturated NO solution was added to the cuvette to begin the reaction. Each assay was run until the absorbance had dropped to zero, that is, when all MV was oxidized.

$\beta$-Galactosidase activities were determined with permeabilized cells from at least three independently grown cultures as previously described (Miller 1972).

The protein concentration of bacteroids and free-living cells solutions was estimated by using the Bio-Rad (Munich, Germany) assay, with a standard curve of varying BSA concentrations.

Leghemoglobin content was measured by fluorimetry as described by LaRue and Child (1978). Nodules (0.3 g) were grounded in $6 \mathrm{ml}$ of $\mathrm{Lb}$ extraction buffer $\left(\mathrm{Na}_{2} \mathrm{HPO}_{4} \cdot 2 \mathrm{H}_{2} \mathrm{O}, 40\right.$ $\mathrm{mM}(\mathrm{pH} 7.4) ; \mathrm{NaH}_{2} \mathrm{PO}_{4} \cdot \mathrm{H}_{2} \mathrm{O}, 10 \mathrm{mM}\left(\mathrm{pH} \mathrm{7.4)} ; \mathrm{K}_{3} \mathrm{Fe}(\mathrm{CN})_{6}\right.$, $0.02 \%$; $\mathrm{NaHCO}_{3}, 0.1 \%$ ) supplemented with $0.1 \mathrm{~g}$ of polyvinylplypirrolidone. The homogenate was centrifugated at $12,000 \times$ $g$ at $4{ }^{\circ} \mathrm{C}$ for $20 \mathrm{~min}$, to retain the supernatant. Clear supernate $(50 \mu \mathrm{l})$ and saturated oxalic acid $(3 \mathrm{ml})$ were added to screwcapped tubes, which were sealed and heated for $30 \mathrm{~min}$ at $120^{\circ} \mathrm{C}$ in an autoclave and, then, cooled to room temperature. The fluorescence of the solutions was measured with a Shimadzu (Shimadzu Scientific Instruments, Kyoto, Japan) spectrophotofluorometer equipped with a mercury-xenon lamp and a RF-549 red-sensitive photomultiplier. The excitation wavelength was $405 \mathrm{~nm}$ and the emission monochromator setting was $650 \mathrm{~nm}$. The difference in fluorescence between heated and unheated samples was proportional to heme protein concentration.

Acetylene-dependent ethylene production was assayed on fresh detached nodules. A Hewlett-Packard model 5890 gas chromatograph (Agilent Technologies, S.L., Madrid) equipped with a flame ionization detector was operated with a molecular sieve 5A (60 to 80 mesh) column $(180 \times 0.32 \mathrm{~cm})$ (Agilent

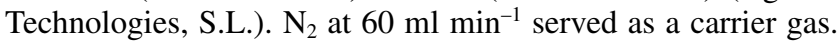
Oven, injector, and detector temperatures were 60, 90, and $110^{\circ} \mathrm{C}$, respectively. Nodules (20 to 30 ) were placed in $17-\mathrm{ml}$ tubes that were filled with $10 \%$ acetylene. Gas samples $(0.5$ $\mathrm{ml}$ ) were taken from the tubes for ethylene analyses after incubation for 10 and $20 \mathrm{~min}$. Concentration of ethylene in each sample was calculated from standards of pure ethylene.

For determination of nitrite in nodules, $0.5 \mathrm{~g}$ of nodules were homogenized with $2 \mathrm{ml}$ of $1 \mathrm{M}$ zinc acetate and were centrifuged at $12,000 \times g$ at $4^{\circ} \mathrm{C}$ for $5 \mathrm{~min}$. For the determination of nitrite in free-living cultures, $1-\mathrm{ml}$ samples of the cultures were centrifuged at $8,000 \times g$ for $3 \mathrm{~min}$, to remove the cells. The resultant supernatants from the nodule extracts or from the cell cultures were mixed with 1 volume of $100 \%$ icecold ethanol and were centrifuged for another $5 \mathrm{~min}$. The nitrite concentration of the final supernatant was determined as described above.

NO production in free-living cells was measured amperometrically using a NO electrode (Apollo 4000, World Precision Instruments, Inc., Sarasota, FL, U.S.A.) comprising a waterjacketed $\left(30^{\circ} \mathrm{C}\right)$ chamber and stirred magnetically. The membrane-covered electrode was situated at the bottom of the chamber above the stirrer. For experimental assays, the chamber was filled with $2 \mathrm{ml}$ of YEM, to which $100 \mu \mathrm{l}$ of a concentrated cell suspension ( $3 \mathrm{mg}$ of protein per milliliter) were added. After the cells had consumed the oxygen present in the chamber by adding $90 \mu \mathrm{l}$ of $1 \mathrm{M}$ sodium succinate, $30 \mu \mathrm{l}$ of $100 \mathrm{mM} \mathrm{NaNO}{ }_{2}$ were added with a Hamilton syringe, and the NO production was analyzed.

\section{Detection of NO in nodules.}

Nodules were detached from roots and were dipped in the solution of a NO scavenger (c-PTIO) (Invitrogen, Carlsbad, CA, U.S.A.) for $30 \mathrm{~min}$ in the dark at $25^{\circ} \mathrm{C}$, as previously described (Shimoda et al. 2009). A set of control nodules were 
treated with distilled water. Detection of NO in nodules was performed as previously described (Nagata et al. 2008). A stock solution of DAF-FM ( $7 \mathrm{mM}$ in dimethylsulfoxide) (Invitrogen) was diluted 1,000-fold in water before use. Nodules were incubated with the diluted DAF-FM solution for $1 \mathrm{~h}$ in the dark at $25^{\circ} \mathrm{C}$. The relative fluorescence units of the DAFFM solution were measured using a fluorometer (QM200; Photon Technology International, Birmingham, NJ, U.S.A.) with $495 \mathrm{~nm}$ excitation and $515 \mathrm{~nm}$ emission wavelength $(2 \mathrm{~nm}$ band width).

\section{Whole-nodule EPR spectroscopy.}

Whole-nodule EPR spectroscopy was performed essentially as described by Meakin and associates (2007). Intact, frozen root nodules (between 2.5 and $2.8 \mathrm{~mm}$ in diameter) were transferred individually to $12-\mathrm{cm}$ quartz EPR tubes with internal diameters of $3 \mathrm{~mm}$, under liquid nitrogen. Each sample contained a total biomass of $160 \pm 10 \mathrm{mg}$. Nodules were closely packed and filled the tube to a depth of approximately $30 \mathrm{~mm}$. A 10-cm length of ethylene-tetrafluoroethylene tubing (GE Healthcare, Piscataway, NJ, U.S.A.) was inserted into the tube and was secured to allow liquid gas boil-off but prevent nodule movement during sample loading and measurement. In the absence of nodules, neither the tubes nor tubing gave rise to any EPR signal. EPR spectra were recorded using a Bruker ER200D spectrometer, fitted with a dual mode cavity (type ER4116DM), which was interfaced to an ELEXSYS control system (Bruker Analytische Messtechnik GmBH, Karlsruhe, Germany) and equipped with a variable temperature liquid helium flow cryostat (Oxford Instruments, Oxfordshire, U.K.). Spectra were recorded at $41 \pm 1 \mathrm{~K}$. Microwave frequency was $9.683 \mathrm{GHz}$ (X-band) with $2 \mathrm{~mW}$ power applied. Spectra are the average of three scans with modulation amplitude $0.3 \mathrm{mT}$ ( 3 Gauss) and signal gain $2.83 \times 10^{4}$.

\section{UV-visible spectroscopy.}

For the quantification of the percentage of Lb bound to NO within nodules, Lb extracts were prepared from nodules by homogenizing $0.3 \mathrm{~g}$ of nodules with $4 \mathrm{ml}$ of $\mathrm{Lb}$ extraction buffer and centrifuging at $12,000 \times g$ at $4^{\circ} \mathrm{C}$ for $20 \mathrm{~min}$ to retain the supernatant. Absorption spectra from 300 to $700 \mathrm{~nm}$ at $20^{\circ} \mathrm{C}$ were recorded from $1 \mathrm{ml}$ of reduced and nitrosylated nodule extracts using a Hitachi U-3310 Spectrophotometer linked to a circulating BC-10 water bath (Fisher Scientific, Fairlawn, NJ, U.S.A.). Absorption measurements were taken from the spectra to allow quantification of the nodular LbNO following the protocol previously described by Meakin and associates (2007).

\section{Transcript levels.}

Nodules were detached from roots, were dipped in a solution of $2 \mathrm{mM} \mathrm{c}$-PTIO for $3 \mathrm{~h}$ in the dark at $25^{\circ} \mathrm{C}$, as previously described (Shimoda et al. 2009), and were frozen in liquid nitrogen. A set of control nodules were treated with distilled water. Total RNA was isolated from nodules using the RNeasy plant mini kit (Qiagen, Hilden, Germany), was treated with DNaseI amplification grade (Invitrogen), and was reverse transcribed using SuperScript II reverse transcriptase (Invitrogen). For each RNA sample, control experiments in which the reverse transcriptase step was omitted were done to confirm the absence of any residual DNA. Quantitative RT-PCR was performed in a iQ5 Real-Time PCR detection system (Bio-Rad) using Platinum Taq DNA polymerase, SYBR green I nucleic acid gel stain and the $10 \mathrm{mM}$ dNTP Set (Invitrogen), and specific primers for genes expressed in bacteroids (Supplementary Table 1). The PCR program consisted of an initial denaturation and Taq activation step of $3 \mathrm{~min}$ at $95^{\circ} \mathrm{C}$, followed by 40 cycles of $15 \mathrm{~s}$ at $95^{\circ} \mathrm{C}, 45 \mathrm{~s}$ at $60^{\circ} \mathrm{C}$, and $45 \mathrm{~s}$ at $72^{\circ} \mathrm{C}$. All reactions were set up in triplicate. The generation of specific PCR products was confirmed by melting curve analysis. The mRNA levels were normalized against gapA gene (Yang et al. 2006). Values of treated nodules were expressed relative to those of control nodules using the $2^{-\Delta \Delta \mathrm{Ct}}$ method (Livak and Schmittgen 2001).

\section{ACKNOWLEDGMENTS}

This work was supported by grant AGL2006-13848-CO2-02/AGR from the Ministerio de Educación y Ciencia, and 107PICO312 from Ciencia y Tecnología para el Desarrollo. Support from the Junta de Andalucía (BIO275 ) is also acknowledged, as is the financial support from Consejo Superior de Investigaciones Científicas (CSIC) (2007GB0035) and from CSIC/Consejo Nacional de Ciencia y Tecnología (2005MX0032) for collaborations with the University of East Anglia (Norwich, U.K.) and Centro de Ciencias Genómicas (Morelos, México). We thank H. Hennecke and H.-M. Fischer for the gift of plasmid pRJ1042. C. Sánchez was supported by a fellowship from the CSIC (I3P). D. J. Richardson is the recipient of a Royal Society Wolfson Merit Award.

\section{LITERATURE CITED}

Acuña, G., Álvarez-Morales, A., Fischer, H.-M., and Hennecke, H. 1987. A vector for the site-directed, genomic integration of foreign DNA into soybean root-nodule bacteria. Plant Mol. Biol. 9:41-50.

Appleby, C.A. 1992. The origin and functions of hemoglobin in plants. Sci. Progress 76:365-398.

Bacanamwo, M., and Purcell, L. C. 1999. Soybean dry matter and N accumulation responses to flooding stress, $\mathrm{N}$ sources and hypoxia. J. Exp. Bot. 50:689-696.

Bailey-Serres, J., and Voesenek, L. A. C. J. 2008. Flooding stress: Acclimations and genetic diversity. Annu. Rev. Plant Biol. 59:313-39.

Baudouin, E., Pleuchot, L., Engler, G., Pauly, N., and Puppo, A. 2006. Nitric oxide is formed in Medicago truncatula-Sinorhizobium meliloti functional nodules. Mol. Plant-Microbe Interact. 19:970-975.

Bedmar, E. J., Robles, E. F., and Delgado, M. J. 2005. The complete denitrification pathway of the symbiotic nitrogen-fixing bacterium Bradyrhizobium japonicum. Biochem. Soc. Trans. 33:141-144.

Besson-Bard, A., Pugin, A., and Wendehenne, D. 2008. New insights into nitric oxide signaling in plants. Annu. Rev. Plant Biol. 59:21-39.

Bethke, P. C., Badger, M. R., and Jones, R. L. 2004. Apoplastic synthesis of nitric oxide by plant tissues. Plant Cell. 16:332-341.

Bueno, E., Richardson, D. J., Bedmar, E. J., and Delgado, M. J. 2009. Expression of Bradyrhizobium japonicum $\mathrm{cbb}_{3}$ terminal oxidase under denitrifying conditions is subjected to redox control. FEMS (Fed. Eur. Microbiol. Soc.) Microbiol. Lett. 298:20-28.

Cruz-Ramos, H., Crack, J., Wu, G., Hughes, M. N., Scott, C., Thomson, A. J., Green, J., and Poole, R. K. 2002. NO sensing by FNR: Regulation of the Escherichia coli NO-detoxifying flavohaemoglobin, Hmp. The EMBO (Eur. Mol. Biol. Organ.) J. 21:3235-3244.

Cueto, M., Hernández-Perera, O., Martín, R., Bentura, M. L., Rodrigo, J., Lamas, S., and Golvano, M. P. 1996. Presence of nitric oxide synthase activity in roots and nodules of Lupinus albus. FEBS (Fed. Eur. Biochem. Soc.) Lett. 398:159-164.

Delgado, M. J., Bedmar, E. J., and Downie, J. A. 1998. Genes involved in the formation and assembly of rhizobial cytochromes and their role in symbiotic nitrogen fixation. Adv. Microbial Phys. 40:191-231.

Delgado, M. J., Bonnard, N., Tresierra-Ayala, A., Bedmar, E. J., and Müller, P. 2003. The Bradyrhizobium japonicum napEDABC genes encoding the periplasmic nitrate reductase are essential for nitrate respiration. Microbiology. 149:3395-3403.

Delledonne, M. 2005. NO news is good news for plants. Curr. Opin. Plant Biol. 8:390-396.

Dordas, C. 2009. Nonsymbiotic haemoglobins and stress tolerance in plants. Plant Sci. 176:433-440.

Ferrarini, A., De Stefano, M., Baudouin, E., Pucciariello, C., Polverari, A., Puppo, A., and Delledonne, M. 2008. Expression of Medicago truncatula genes responsive to nitric oxide in pathogenic and symbiotic conditions. Mol. Plant-Microbe Interact. 21:781-790.

Fischer, H.-M. 1994. Genetic regulation of nitrogen fixation in rhizobia. Microbiol. Rev. 58:352-386.

Gilles-González, M. A., González, G., and Perutz, M. F. 1994. Hemebased sensors, exemplified by the kinase FixL, are a new class of heme protein with distinctive ligand binding and autoxidation. Biochemistry. 33:8067-8073.

Herold, S., and Puppo, A. 2005. Oxyleghemoglobin scavenges nitrogen monoxide and peroxynitrite: A possible role in functioning nodules? J. Biol. Inorg. Chem. 10:935-945. 
Kaneko, T., Nakamura, Y., Sato, S., Minamisawa, K., Uchiumi, T., Sasamoto, S., Watanabe, A., Idesawa, K., Iriguchi, M., Kawashima, K., Kohara, M., Matsumoto, M., Shimpo, S., Tsuruoka, H., Wada, T., Yamada, M., and Tabata, S. 2002. Complete genomic sequence of nitrogen-fixing symbiotic bacterium Bradyrhizobium japonicum USDA110. DNA Res. 9:189-197.

Kato, K., Kanahama, K., and Kanayama, Y. 2009. Involvement of nitric oxide in the inhibition of nitrogenase activity by nitrate in Lotus root nodules. J. Plant. Physiol. Epub ahead of print.

LaRue, T. A., and Child, J. J. 1979. Sensitive fluorometric assay for leghemoglobin. Ana. Biochem. 92:11-15.

Lin, J. T., and Stewart, V. 1998. Nitrate assimilation by bacteria. Adv. Micro. Phys. 39:1-30.

Livak, K. J., and Schmittgen, T. D. 2001. Analysis of relative gene expression data using real-time quantitative PCR and the 2[-Delta Delta $\mathrm{C}(\mathrm{T})$ ] method. Methods. 25:402-408.

Mathieu, C., Moreau, S., Frendo, P., Puppo, A., and Davies, M. J. 1998 Direct detection of radicals in intact soybean nodules: Presence of nitric oxide-leghemoglobin complexes. Free. Radic. Biol. Med. 24:12421249

Meakin, G. E., Jepson, B., Bedmar, E. J., Richardson, D. J., and Delgado, M. J. 2006. The role of Bradyrhizobium japonicum nitric oxide reductase in nitric oxide detoxification in soya bean root nodules. Biochem. Soc. Trans. 34:195-196.

Meakin, G. E., Bueno, E., Jepson, B., Bedmar, E. J., Richardson, D. J., and Delgado, M. J. 2007. The contribution of bacteroidal nitrate and nitrite reduction to the formation of nitrosylleghaemoglobin complexes in soybean root nodules. Microbiology. 153:411-419.

Mesa, S., Velasco, L., Manzanera, M. E., Delgado, M. J., and Bedmar, E. J. 2002. Characterization of the norBCOD genes, encoding nitric oxide reductase, in the nitrogen fixing bacterium Bradyrhizobium japonicum. Microbiology. 148:3553-3560.

Mesa, S., de Dios Alché, J., Bedmar, E. J., and Delgado, M. J. 2004. Expression of the nir, nor and nos denitrification genes from Bradyrhizobium japonicum in soybean root nodules. Physiol. Plantarum. 120:205211.

Mesa, S., Hauser, F., Friberg, M., Malaguti, E., Fischer, H.-M., and Hennecke, H. 2008. Comprehensive assessment of the regulons controlled by the FixLJ-FixK ${ }_{2}-$ FixK $_{1}$ cascade in Bradyrhizobium japonicum. J. Bacteriol. 190:6568-6579.

Meyer, C., Lea, U. S., Provan, F., Kaiser, W. M., and Lillo, C. 2005. Is nitrate reductase a major player in the plant NO (nitric oxide) game? Photosyn. Res. 83:181-189.

Miller, J. H. 1972. Experiments in Molecular Genetics. Cold Spring Harbor Laboratory Press, New York.

Minchin, F. R. 1997. Regulation of oxygen diffusion in legume nodules. Soil. Biol. Biochem. 29:881-888.

Nagata, M., Murakami, E.-i., Shimoda, Y., Shimoda-Sasakura, F., Kucho, K.-i., Suzuki, A., Abe, M., Higashi, S., and Uchiumi, T. 2008. Expression of a class 1 hemoglobin gene and production of nitric oxide in response to symbiotic and pathogenic bacteria in Lotus japonicus. Mol. Plant-Microbe Interact. 21:1175-1183.

Nicholas, D. J. D., and Nason, A. 1957. Determination of nitrate and nitrite. Pages 981-984 in: Methods in Enzymology. S. P. Colowick and N. O.Kaplan, eds. Academic Press, New York.

Pauly, N., Pucciariello, C., Mandon, K., Innocenti, G., Jamet, A., Baudouin, E., Hérouart, D., Frendo, P., and Puppo, A. 2006. Reactive oxygen and nitrogen species and glutathione: Key players in the legume-Rhizobium symbiosis. J. Exp. Bot. 57:1769-1776.

Pii, Y., Crimi, M., Cremonese, G., Spena, A., and Pandolfini, T. 2007. Auxin and nitric oxide control indeterminate nodule formation. BMC Plant Biol. 8:7-21.

Pullan, S. T., Gidley, M. D., Jones, R. A., Barrett, J., Stevanin, T. M., Read, R. C., Green, J., and Poole, R. K. 2008. Nitric oxide in chemostat- cultured Escherichia coli is sensed by Fnr and other global regulators: Unaltered methionine biosynthesis indicates lack of $\mathrm{S}$ nitrosation. J. Bacteriol. 189:1845-1855.

Regensburger, B., and Hennecke, H. 1983. RNA polymerase from Rhizobium japonicum. Arch. Microbiol. 135:103-109.

Rigaud, J., and Puppo, A. 1975. Indole-3-acetic acid catabolism by soybean bacteroids. J. Gen. Microbiol. 88:223-228.

Sasakura, F., Uchiumi, T., Shimoda, Y., Suzuki, A. Takenouchi, K., Higashi, S., and Abe, M. 2006. A class 1 hemoglobin gene from Alnus firma functions in symbiotic and nonsymbiotic tissues to detoxify nitric oxide. Mol. Plant-Microbe Interact. 19:441-450.

Shimoda, Y., Nagata, M., Suzuki, A., Abe, M., Sato, S., Kato, T., Tabata, S., Higashi, S., and Uchiumi, T. 2005. Symbiotic rhizobium and nitric oxide induce gene expression of non-symbiotic hemoglobin in Lotus japonicus. Plant Cell Physiol. 46:99-107.

Shimoda, Y., Shimoda-Sasakura, F., Kucho, K., Kanamori, N., Nagata, M. Suzuki, A., Abe, M., Higashi, S., and Uchiumi, T. 2009. Overexpression of class 1 plant hemoglobin genes enhances symbiotic nitrogen fixation activity between Mesorhizobium loti and Lotus japonicus. Plant J. 57:254-63.

Stöhr, C., Strube, F., Marx, G., Ullrich, W. R., and Rockel, P. 2001. A plasma membrane-bound enzyme of tobacco roots catalyses the formation of nitric oxide from nitrite. Planta 212:835-841.

Trinchant, J.-C., and Rigaud, J. 1982. Nitrite and nitric oxide as inhibitors of nitrogenase from soybean bacteroids. Appl. Environ. Microbiol. 44:1385-1388.

van Spanning, R. J., Delgado, M. J., and Richardson, D. J. 2005. The nitrogen cycle: Denitrification and its relationship to $\mathrm{N}_{2}$ fixation. Pages 277-342 in: Nitrogen Fixation in Agriculture, Forestry, Ecology and the Environment. D.Werner, and W. E. Newton, eds. Springer Netherlands, Dordrecht, The Netherlands.

van Spanning, R. J., Richardson, D. J., and Ferguson, S. J. 2007. Introduction to the biochemistry and molecular biology of denitrification. Pages 3-20 in: Biology of the Nitrogen Cycle. H. Bothe, S. J. Ferguson, and W. E. Newton, eds. Elsevier, Amsterdam.

Velasco, L., Mesa, S., Delgado, M. J., and Bedmar, E. J. 2001. Characterization of the nirK gene encoding the respiratory, $\mathrm{Cu}$-containing nitrite reductase of Bradyrhizobium japonicum. Biochim. Biophys. Acta. 1521:130-134.

Velasco, L., Mesa, S., Xu, C., Delgado, M. J., and Bedmar, E. J. 2004 Molecular characterization of nosRZDFYLX genes coding for denitrifying nitrous oxide reductase of Bradyrhizobium japonicum. Antonie van Leeuwenhoek 85:229-235.

Vincent, J. M. 1974. Root-nodule symbioses with Rhizobium. Pages 265 341 in: The Biology of Nitrogen Fixation. A. Quispel, ed. Elsevier, New York.

Winkler, W. C., Gonzalez, G., Wittenberg J. B., Hille, R., Dakappagari, N., Jacob, A., González, L. A., and Gilles, M. A. 1996. Nonsteric factors dominate binding of nitric oxide, azide, imidazole, cyanide, and fluoride to the rhizobial heme-based oxygen sensor FixL. Chem. Biol 3:841-850.

Yamasaki, H., Sakihama, Y., and Takahashi, S. 1999. An alternative pathway for nitric oxide production in plants: New features of an old enzyme. Trends Plant Sci. 4:128-129.

Yamasaki, H., and Sakihama, S. 2000. Simultaneous production of nitric oxide and peroxynitrite by plant nitrate reductase: In vitro evidence for the NR-dependent formation of active nitrogen species. FEBS (Fed. Eur. Biochem. Soc.) Lett. 468:89-92.

Yang, J., Sangwan, I., Lindemann, A., Hauser, F., Hennecke H., Fischer H.-M., and O'Brian, M. R. 2006. Bradyrhizobium japonicum senses iron through the status of haem to regulate iron homeostasis and metabolism. Mol. Microbiol. 60:427-437.

Zumft, W. G. 1997. Cell biology and molecular basis of denitrification. Microbiol. Mol. Biol. Rev. 61:533-616. 